\title{
AEROBIC BACTERIOLOGICAL PROFILE OF AFB NEGATIVE SPUTUM SAMPLES AT A TERTIARY CARE MEDICAL INSTITUTE IN EASTERN INDIA
}

\author{
Gurumayum Preeti ${ }^{1}$, Supriya Laifangbam²
}

${ }^{1}$ Demonstrator, Department of Microbiology, Jawaharlal Nehru Institute of Medical Sciences, Imphal.

${ }^{2}$ Associate Professor, Department of Microbiology, Jawaharlal Nehru Institute of Medical Sciences, Imphal.

\begin{tabular}{l}
\hline ABSTRACT \\
BACKGROUND \\
Lower Respiratory Tract Infection (LRTI) is a leading cause of morbidity and mortality. Many of the patients suspected of \\
suffering from Tuberculosis (TB) and referred to the Revised National Tuberculosis Control Programme (RNTCP) centre usually \\
turn out to be suffering from non-tuberculous LRTIs and end up receiving no specific treatment.
\end{tabular}

\section{AIMS}

1. To isolate aerobic bacterial pathogens other than Mycobacteria spp. from AFB negative sputum samples. 2. To determine the antibiotic sensitivity pattern of the isolates.

\section{SETTINGS AND DESIGN}

A cross-sectional study was conducted at the Microbiology Department of a tertiary care medical institute on existing data for a period of four years (2011-2015).

\section{METHODS AND MATERIAL}

1015 AFB negative sputum samples were collected. Aerobic bacterial culture identification and antibiotic sensitivity tests were carried out following standard laboratory procedures.

\section{STATISTICAL ANALYSIS}

Data analysis was performed by using IBM SPSS version 21 software. Descriptive statistics were derived using frequency, percentage, and proportion. Chi-square test was used to calculate the P-values.

\section{RESULTS}

Among the 904 bacterial isolates, 613 (67.8\%) were Gram-Negative Bacilli (GNB) and 291 (32.1\%) were Gram-Positive Cocci (GPC). The most common organism isolated was Pseudomonas aeruginosa (38.9\%) followed by Staphylococcus aureus (30\%); out of which 25\% were Methicillin-Resistant Staphylococcus Aureus (MRSA) and Klebsiella pneumoniae (15.7\%). Pseudomonas aeruginosa was sensitive to carbapenems, aminoglycosides, and $\beta$ lactam- $\beta$ lactamase inhibitor combination. The GPCs were highly sensitive to linezolid and vancomycin. The Enterobacteriaceae isolates were highly susceptible to carbapenems and $\beta$ lactam- $\beta$ lactamase inhibitor combination.

\section{CONCLUSION}

Pseudomonas aeruginosa has been found to be the most commonly isolated aerobic bacteria from the AFB negative sputum samples. Antibiogram helps in specific treatment during the management of non-tuberculous LRTI as most of the isolated bacteria have been observed to be highly resistant to the commonly used antibiotics.

\section{KEYWORDS}

Sputum, Bacteriology, Pseudomonas Aeruginosa.

HOW TO CITE THIS ARTICLE: Preeti G, Laifangbam S. Aerobic bacteriological profile of AFB negative sputum samples at a tertiary care medical institute in eastern India. J. Evolution Med. Dent. Sci. 2016;5(58):4022-4026, DOI: 10.14260/jemds/2016/920

\section{INTRODUCTION}

Lower Respiratory Tract Infection (LRTI) is currently the seventh leading cause of death and disability. It is stated that LRTI will become the third leading cause of death by 2020, next to heart and cerebrovascular diseases. Six hundred million people worldwide have LRTI.[1,2,3]

Financial or Other, Competing Interest: None.

Submission 23-05-2016, Peer Review 07-07-2016,

Acceptance 13-07-2016, Published 20-07-2016.

Corresponding Author:

Dr. Supriya Laifangbam,

BSCC, Uripok Flyover Point,

Imphal West-795001,

Manipur.

E-mail: slaifangbam@gmail.com

DOI: $10.14260 /$ jemds/2016/920
Every year, Acute Respiratory Tract Infection (ARTI) in young children is responsible for an estimated 3.9 million deaths throughout the world. ${ }^{[4,5]}$ LRTIs have been attributed to account for almost $20 \%$ mortality among the infectious disease deaths in India.[6]

LRTIs are mostly mild, transient, and self-limiting. Due to this, many infected persons tend to disregard them. In developing countries, the situation is more complicated and management is often difficult due to the problem associated with the identification of the aetiological agents and administration of appropriate treatment in cases requiring antibiotic therapy. The aetiology and symptomatology of respiratory disease differ with age, gender, season, the type of population at risk, and other factors. Gram-positive bacteria (GPC) such as Staphylococcus aureus and Streptococcus 
pneumoniae and gram-negative bacteria (GNB) like Haemophilus influenzae, Pseudomonas (spp.), Acinetobacter spp., and Klebsiella spp. have been recovered from LRTIs.[7]

With the ever increasing population of immunocompromised patients such as elderly patients, Human Immunodeficiency Virus (HIV) infected, cancer, diabetic patients, etc. the isolation of opportunistic bacteria like Pseudomonas spp., Acinetobacter spp., Haemophilus spp. etc. have been seen to be on the rise. ${ }^{[8]}$ Such opportunistic bacteria are usually resistant to most of the antibiotics used for empirical treatment. The aetiological agents cannot be determined clinically, which vary from area to area and so does their antibiotic susceptibility profile. However, knowledge about the prevalence of microbial agents causing LRTIs in this part of eastern India is sparse. Moreover, many of the patients suspected of suffering from Tuberculosis (TB) attend Revised National Tuberculosis Control Programme (RNTCP) Centre. But, they usually turn out to be suffering from non-tuberculous LRTIs and are left without any specific treatment. In resource, poor settings of an economically developing country like India more so in the eastern states where molecular methods of diagnosis may not be available performing conventional sputum culture and antibiotic sensitivity tests are still effective in providing proper patient care. So, our study aims to detect the aerobic bacterial pathogens of LRTIs other than Mycobacteria spp. and to analyse their antibiogram.

\section{MATERIALS AND METHODS}

A cross-sectional study was conducted using laboratory data dating from January 2011 to December 2015 at the Microbiology Department of a tertiary care medical institute in Eastern India. The protocol of the present research work was approved by the institutional ethical committee. A total of 1015 sputum samples were collected from the designated microscopy centre attached to this department under the RNTCP. All patients $<18$ years of age and those who were sputum Acid-Fast Positive (AFB) were excluded from the study. A detailed clinical history regarding the age, gender, marital status, education, onset, duration and nature of illness, and history of past medication were recorded in a predesigned proforma.

Deeply coughed up sputum samples were collected into a sterile container and were processed immediately. Direct microscopy of Gram stained smear was done and examined for pus cells, epithelial cells, and bacteria. Those specimen with $\geq 25$ pus cells and $\leq 10$ epithelial cells per high-powered field were inoculated onto MacConkey agar (MA), sheep blood agar (SBA), and chocolate agar (CA). MA plates were incubated in ambient air at $37^{\circ} \mathrm{C}$ while SBA and CA plates were kept in a candle jar at $37^{\circ} \mathrm{C}$ for overnight incubation.

Based upon the Gram stain morphology, colony characteristic, and motility, the biochemical tests and other special tests were done. They were performed according to the standard procedures.[9] The tests performed to identify the GPCs Gram-Positive Cocci (GPCs) were catalase, slide coagulase, mannitol fermentation, novobiocin resistance, optochin sensitivity, bacitracin sensitivity, and bile solubility tests. The first test performed for GNB was oxidase test. Those GNBs, which were oxidase negative (Enterobacteriaceae) were subjected to catalase, indole production, methyl red, Voges-Proskauer, citrate utilisation, urease, triple sugar iron, nitrate reduction, sugar fermentation, and amino acid decarboxylation tests. Those GNBs, which were oxidase positive were further subjected to tests like catalase, nitrate reduction, citrate utilization, and Hugh-Leifson oxidation-fermentation tests.

The antibiotic susceptibility was done on Mueller-Hinton agar except for Streptococcus pneumoniae, which was done on SBA. After overnight incubation, the zone sizes were noted and the results were interpreted as sensitive or resistant comparing with Kirby-Bauer standard chart.[10] Cefoxitin (30 ug) antibiotic disc was used for detection of MethicillinResistant Staphylococcus Aureus (MRSA). The antibiotics used are given in Table 1.

All the data was entered into Microsoft Excel 2007 spreadsheet and analysed using IBM SPSS software version 21. Descriptive statistics were derived using frequency, percentage, and proportion. Chi-square test was used to calculate the P-values.

\section{RESULTS}

In our present study, a total of 1015 sputum samples negative for AFB were processed and analysed, out of which 689 (67.9\%) belonged to IPD (Inpatient Department) and 326 (32\%) to OPD (Outpatient Department) Among the IPD patients, maximum sputum samples were received from Medicine and TB and Chest Medicine Departments. (Table 2). The age group of the patients included in the present study ranged from 18 to 80 years. Out of 904 (89\%) patients from whom bacteria were isolated, maximum number $278(27.3 \%)$ belonged to the age group of 61-75 years. 595 were males and 309 were females. The male:female ratio is $1.93: 1.626$ patients were found to be associated with various risk factors and co-morbid conditions (Table 3). $25.3 \%$ of the patients were found to be chronic smokers or ex-smokers and $24.1 \%$ of the patients were found to be HIV positive. $613(67.8 \%)$ were GNBs and 291 (32.1\%) were GPCs. Pseudomonas aeruginosa was the commonest bacteria isolated in 352 (38.9\%) cases, followed by S. aureus isolated in 271 (30\%) [MSSA $=204 ; M R S A=67]$, and K. pneumoniae isolated in 142 $(15.7 \%)$ cases. Other organisms isolated were E. coli in 65 (7.1\%), K. oxytoca in $26(2.8 \%)$, St. pneumoniae in 20 (2.2\%), C. koseri in 19 (2.1\%), and P. vulgaris in $9(0.9 \%)$ of the cases (Table 4).

84\% $(\mathrm{P}=0.033)$ of Pseudomonas aeruginosa isolates were found to be sensitive to the carbapenems. $74 \%(\mathrm{P}=0.046)$ of the isolates were sensitive to piperacillin-tazobactam. $90 \%$ $(\mathrm{P}=0.041)$ of them were resistant to both ceftazidime and cefepime (Table 5). 97\% (P=0.009) and $80.5 \%(\mathrm{P}=0.016)$ of $\mathrm{S}$. aureus were found to be sensitive to linezolid and vancomycin respectively. All of the isolates were found to be resistant to penicillin (Table 6). Antibiotic susceptibility pattern of Klebsiella pneumoniae showed it was most sensitive to the carbapenems, i.e., imipenem and meropenem (97.5\%, $\mathrm{p}=0.031 ; 95 \%, \mathrm{P}=0.037$ respectively) (Table 7).

\begin{tabular}{|c|c|c|}
\hline GPC & Enterobacteriaceae & Pseudomonas \\
\hline $\begin{array}{c}\text { Amoxicillin } \\
(10 \mu \mathrm{g})\end{array}$ & $\begin{array}{c}\text { Amoxicillin } \\
(10 \mu \mathrm{g})\end{array}$ & Gentamicin $(10 \mu \mathrm{g})$ \\
\hline $\begin{array}{c}\text { AmoxyClav } \\
(20+10 \mu \mathrm{g})\end{array}$ & $\begin{array}{c}\text { AmoxyClav } \\
(20+10 \mu \mathrm{g})\end{array}$ & Amikacin $(30 \mu \mathrm{g})$ \\
\hline $\begin{array}{c}\text { Co-trimoxazole } \\
(25 \mu \mathrm{g})\end{array}$ & $\begin{array}{c}\text { Ciprofloxacin } \\
(5 \mu \mathrm{g})\end{array}$ & $\begin{array}{c}\text { Piperacillin+Tazobactam } \\
(100+10 \mu \mathrm{g})\end{array}$ \\
\hline $\begin{array}{c}\text { Tetracycline } \\
(30 \mu \mathrm{g})\end{array}$ & $\begin{array}{c}\text { Gentamicin } \\
(10 \mu \mathrm{g})\end{array}$ & $\begin{array}{c}\text { AmoxyClav } \\
(20+10 \mu \mathrm{g})\end{array}$ \\
\hline
\end{tabular}




\begin{tabular}{|c|c|c|}
\hline $\begin{array}{c}\text { Erythromycin } \\
(15 \mu \mathrm{g})\end{array}$ & $\begin{array}{c}\text { Amikacin } \\
(30 \mu \mathrm{g})\end{array}$ & $\begin{array}{c}\text { Imipenem } \\
(10 \mu \mathrm{g})\end{array}$ \\
\hline Penicillin & Cefepime & Meropenem \\
$(10$ units $)$ & $(30 \mu \mathrm{g})$ & $(10 \mu \mathrm{g})$ \\
\hline $\begin{array}{c}\text { Vancomycin } \\
(30 \mu \mathrm{g})\end{array}$ & Cefotaxime & Ciprofloxacin \\
$(30 \mu \mathrm{g})$ & $(30 \mu \mathrm{g})$ \\
\hline $\begin{array}{c}\text { Ciprofloxacin } \\
(5 \mu \mathrm{g})\end{array}$ & Imipenem & Ceftazidime \\
$(10 \mu \mathrm{g})$ & $(30 \mu \mathrm{g})$ \\
\hline Clindamycin & Meropenem & Ticarcillin+Clavulanic \\
$(2 \mu \mathrm{g})$ & $(10 \mu \mathrm{g})$ & acid $(75+10 \mu \mathrm{g})$ \\
\hline Linezolid & Piperacillin+ & \\
$(30 \mu \mathrm{g})$ & Tazobactam & $(100+10 \mu \mathrm{g})$ \\
\hline \multicolumn{3}{|c|}{ Table 1: Antibiotics Used } \\
\hline
\end{tabular}

\begin{tabular}{|c|c|}
\hline \multicolumn{2}{|c|}{ Table 3: Patient Characteristics } \\
\hline Organisms & Number of Isolates \\
\hline P. aeruginosa & $352(38.9 \%)$ \\
\hline S. aureus & $271(30 \%)[\mathrm{MSSA}=204 ; \mathrm{MRSA}=67]$ \\
\hline K. pneumoniae & $142(15.7 \%)$ \\
\hline E. coli & $65(7.1 \%)$ \\
\hline K. oxytoca & $26(2.8 \%)$ \\
\hline St. pneumoniae & $20(2.2 \%)$ \\
\hline C. koseri & $19(2.1 \%)$ \\
\hline P. vulgaris & $9(0.9 \%)$ \\
\hline Total & $\mathbf{9 0 4}$ \\
\hline \multicolumn{2}{|c|}{ Table 4: Bacteriological Isolates } \\
\hline
\end{tabular}

\begin{tabular}{|c|c|c|}
\hline & $\begin{array}{c}\text { Medicine and Allied } \\
\text { Departments* }\end{array}$ & $\begin{array}{c}\text { Surgery and Allied } \\
\text { Departments** }\end{array}$ \\
\hline Wards & $451(65.6)$ & $177(25.7)$ \\
\hline ICUs & $37(5.3)$ & $24(3.4)$ \\
\hline Total & 488 & 201 \\
\hline \multicolumn{2}{|c|}{ Table 2: Ward Wise Distribution of IPD Patients (N=689) } \\
\hline
\end{tabular}

*Medicine and Allied Departments-Medicine, TB and Chest

Medicine, etc.

**Surgery and allied Departments-Surgery, Orthopaedics,

Eye, ENT, Obs, and Gynae, etc.

\begin{tabular}{|c|c|c|}
\hline Characteristics & $\begin{array}{c}\text { Number of } \\
\text { patients }\end{array}$ & Percentage \\
\hline Age & & \\
\hline $18-30$ yrs. & 217 & 24 \\
\hline $31-45$ yrs. & 199 & 22 \\
\hline $46-60$ yrs. & 227 & 25 \\
\hline $61-75$ yrs. & 247 & 27.5 \\
\hline$>76$ yrs. & 14 & 1.5 \\
\hline Sex & & \\
\hline Male & 595 & 66 \\
\hline Female & 309 & 34 \\
\hline Male:Female & $1.93: 1$ & \\
\hline Risk Factors & & 25.3 \\
\hline Smoking & 229 & 24.1 \\
\hline HIV & 218 & 9.7 \\
\hline Past Lung Infections & 88 & 6 \\
\hline COPD & 55 & 3.2 \\
\hline Diabetes & 29 & 0.07 \\
\hline Patients with Neoplasm & 7 & \\
\hline
\end{tabular}

\begin{tabular}{|c|c|}
\hline Drugs & Sensitivity \\
\hline AmoxyClav & $138(39.2)$ \\
\hline Ciprofloxacin & $172(48.8)$ \\
\hline Gentamicin & $243(69)$ \\
\hline Imipenem & $296(84)$ \\
\hline Meropenem & $296(84)$ \\
\hline Piperacillin+Tazobactam & $261(74)$ \\
\hline Ceftazidime & $34(9.6)$ \\
\hline Amikacin & $226(64.2)$ \\
\hline Ticarcillin+Clavulanic Acid & $157(44.6)$ \\
\hline Cefepime & $34(9.6)$ \\
\hline Colistin & $174(48.9)$ \\
\hline Table 5: Drug Sensitivity Pattern of \\
Pseudomonas aeruginosa (N=352)
\end{tabular}

\begin{tabular}{|c|c|c|}
\hline Drugs & S. aureus & St. pneumoniae \\
\hline Amoxicillin & $90(33.2)$ & - \\
\hline AmoxyClav & $97(35.7)$ & $20(100)$ \\
\hline Co-trimoxazole & $150(55.3)$ & $0(0)$ \\
\hline Ciprofloxacin & $218(80.4)$ & $16(80)$ \\
\hline Clindamycin & $90(33.2)$ & - \\
\hline Penicillin & $0(0)$ & $0(0)$ \\
\hline Vancomycin & $218(80.5)$ & $8(40)$ \\
\hline Erythromycin & $150(55.3)$ & $8(40)$ \\
\hline Tetracycline & $218(80.4)$ & - \\
\hline Linezolid & $262(97)$ & - \\
\hline Table 6: Drug Sensitivity Pattern of GPC Isolates N (\%) \\
\hline
\end{tabular}

\begin{tabular}{|c|c|c|c|c|c|}
\hline Drugs & K. pneumoniae & K. oxytoca & E. coli & P. vulgaris & C. koseri \\
\hline AmoxyClav & $35(25)$ & $23(88.4)$ & $39(60)$ & $9(100)$ & $16(84.2)$ \\
\hline Ciprofloxacin & $32(22.5)$ & $23(88.4)$ & $39(60)$ & $9(100)$ & $0(0)$ \\
\hline Gentamicin & $74(52.5)$ & $23(88.4)$ & $47(72)$ & $8(88.8)$ & $8(42)$ \\
\hline Amikacin & $78(55)$ & $23(88.4)$ & $23(35)$ & $8(88.8)$ & $16(84.2)$ \\
\hline Cefepime & $60(42.5)$ & $15(57.7)$ & $32(49)$ & $8(88.8)$ & $8(42)$ \\
\hline Cefotaxime & $53(37.5)$ & $17(65.3)$ & $36(55.4)$ & $5(55.6)$ & $9(47.3)$ \\
\hline Meropenem & $138(97.5)$ & $26(100)$ & $65(100)$ & $9(100)$ & $16(84.2)$ \\
\hline Imipenem & $138(97.5)$ & $26(100)$ & $65(100)$ & $9(100)$ & $19(100)$ \\
\hline Piperacillin+ Tazobactam & $88(62.5)$ & $7(26.9)$ & $16(24.6)$ & $9(100)$ & $16(84.2)$ \\
\hline Ceftazidime & $21(15)$ & $7(26.9)$ & $23(35)$ & $0(0)$ & $0(0)$ \\
\hline Ceftazidime+ Clavulanic Acid & $78(55)$ & $23(88.4)$ & $23(35)$ & $8(88.8)$ & $16(84.2)$ \\
\hline Cefoxitin & $73(37.5)$ & $76(26.9)$ & $16(24.6)$ & $0)$ & $8(42)$ \\
\hline
\end{tabular}




\section{DISCUSSION}

In the present study, the age group of patients ranged from 18-80 years. Majority of the patients belonged to the age group of 61-75 years. Similar findings have been reported in other studies.[4,10] Patients in older age groups are more susceptible to LRTIs because of the effect of ageing on immunity and pulmonary defences, underlying chronic diseases, silent aspiration, increased exposure to institutional care.[11] This was unlike a study where the maximum number of patients belonged to 21-40 years of age.[12] Another study found that patients aged $<60$ years significantly had more incidence of LRTI than patients aged $\geq 60$ years.[13]

Male:female ratio in our study was found to be 1.93:1, which showed the male preponderance. Our finding is consistent with other studies.[12,14,15] The male preponderance could be due to the fact that they are more ambulatory and more exposed to the associated risk factors like smoking, use of tobacco, Chronic Obstructive Pulmonary Disease (COPD), alcoholism, etc.[14] But, a study conducted in Nigeria found female preponderance than male.[16] The associated risk factors identified in our study were smoking, Human Immunodeficiency Virus (HIV), past lung infections, COPD, diabetes, and neoplasm. Similar findings have already been reported in other studies.[17]

In the present study, bacterial pathogens could be isolated in $89 \%$ of the cases, which is similar to other studies.[1,6] The inability to isolate any bacteria in the remaining $11 \%$ of the cases could be due to prior antibiotic administration or due to inability to culture other causative agents like anaerobic bacteria, Chlamydia spp., Legionella spp., Mycoplasma spp., etc. Majority of the isolates in our study were GNBs. This is in accordance to other studies.[4,17,18] In our study, the most common organism isolated was Pseudomonas aeruginosa (38.9\%) followed by S. aureus (30\%; out of which $25 \%$ were MRSA) and K. pneumoniae (15.7\%). These results obtained were not in accordance to most of the other studies.[12,14,15] The increased incidence of Pseudomonas isolates in our study maybe because of the following reasons. The first reason maybe that a large number of our patients were HIV positive, 218 i.e., $24 \%$ of the total 904 . Out of these 218 patients, 176 were IPD patients. Manipur is one of the six high prevalence states in India regarding HIV infection.[19] Non-fermentative bacteria like Pseudomonas aeruginosa usually cause disease by colonizing and subsequently infecting the immunocompromised hosts. They have been incriminated as emerging opportunistic pathogen especially from hospital settings. ${ }^{[20]}$ Another reason maybe that majority of the patients $(67.9 \%)$ belonged to IPD implicating the possibility of hospital-acquired infection. Pseudomonas causes notorious hospital-acquired infections. They are not the common causes of LRTI. We had promptly notified the hospital infection control committee of the institute and stringent actions were taken up to avoid such incidences in future.

In our study, Pseudomonas aeruginosa showed maximum sensitivity to carbapenems, aminoglycosides, and piperacillin-tazobactam combination. They were highly resistant to the third and fourth generation cephalosporins. Similar findings were seen in other studies.[12,14] S. aureus isolates in our study were found to be highly sensitive to linezolid and vancomycin. They were $100 \%$ resistant to penicillin, which is also found in other studies.[12,14,18] In the present study, the K. pneumoniae isolates were found to be most sensitive to the carbapenems and piperacillintazobactam combination and highly resistant to the third generation cephalosporins and quinolones. This is in accordance to other studies.[12,14,17]

The strength of our study is that a single experienced technician performed the sputum culture identification and antibiotic sensitivity tests relevant in the study, which rendered consistent results. Our study happens to be from a newly established medical institute and is the only one of its kind from this Indian state. Inclusion of anaerobic and fastidious bacterial pathogen culture methods would have been able to further validate our present findings. Inability to include cultivation methods for viral and mycological pathogens is another drawback of our study.

\section{CONCLUSION}

Pseudomonas aeruginosa has been found to be the most commonly isolated aerobic bacteria from the AFB negative sputum samples. The result infers the need to strengthen our hospital infection control policies. Antibiogram helps in specific treatment during the management of nontuberculous LRTI as most of the isolated bacteria have been observed to be highly resistant to the commonly used antibiotics.

\section{REFERENCES}

1. Gerard R, Kasturi T, Yuvaranjan S. Bacterial agents causing acute exacerbations in COPD patients, their antibiograms to ESBL production in a tertiary care hospital, India. Int J Curr Microbiol App Sci 2013;2(11):273-82.

2. Priyanka PB, Tukaram PK. Bacterial causes of lower respiratory tract infection in patients attending central referral hospital, Gangtok with reference to antibiotic resistance pattern. Journal of Evolution of Medical and Dental Sciences 2013;2(42):8126-35.

3. Buddha BB, Rajan KD, Nabin K, et al. Retrospective audit of LRTI from sputum samples with respect to Acinetobacter spp., pseudomonas spp., and Klebsiella spp. from tertiary care hospital of Nepal. Int J Med Health Sci 2013;2(3):266-74.

4. Sony S, Acharya A, Gautam A, et al. Lower respiratory tract pathogens and their antimicrobial susceptibility pattern in a medical hospital of central Nepal. International Journal of Biomedical And Advance Research 2013;4(5):335-40.

5. Elkorashy R, Elsherif RH. Gram-negative organisms as a cause of acute exacerbation of COPD. Egyptian Journal of Chest Disease 2014;63(2):345-9.

6. Ramana KV, Anand K, Mohan R, et al. Aetiology and antimicrobial susceptibility patterns of lower respiratory tract infections in a rural tertiary care teaching hospital at Karimnagar, South India. American Journal of Infectious Diseases and Microbiology 2013;1(5):101-5.

7. Khan S, Singh P, Ansari M, et al. Bacteria aetiological agents causing lower respiratory tract infections in the western part of Nepal. Ibnosia J Med BS 2014;6(1):3-8.

8. Graevenitz AV. The role of opportunistic bacteria in human diseases. Ann Rev Microbial 1977;31:447-71. 
9. Collee JG, Fraser AG, Marmion BP, et al. Mackie and McCartney practical medical microbiology. 14th ed. New York, Churchill-Livingstone 1999.

10. CLSI. Performance standards for antimicrobial susceptibility testing twenty-fourth informational supplement. Document M100-s23. Wayne PA: Clinical and laboratory standard institute 2013;33(1).

11. Ahmed SM, Jakribettu RP, Meletath SK, et al. Lower respiratory tract infections: an insight into the prevalence and the antibiogram of the gram negative, respiratory, bacterial agents. Journal of Clinical and Diagnostic Research 2013;7(2):253-6.

12. Preeti S, Pappu K, Nirwan PS, et al. Bacteriological profile and antibiogram pattern of lower respiratory tract infections in a tertiary care hospital in northern India. IJPRBS 2013;2(3):225-33.

13. Ruiz M, Ewig S, Marcos MA, et al. Aetiology of community acquired pneumonia: impact of age, comorbidity and severity. Am J Respir Crit Care Med 1999;160(2): 397-405.

14. Tripathi PC, Dhote K. Lower respiratory tract infections: current aetiological trends and antibiogram. J Pharm Biomed Sci 2014;4(3):249-55.
15. Supriya P, Prema NB, Ramani TV. Lower respiratory tract infection-bacteriological profile and antibiogram pattern. Int J Curr Res Rev 2012;4(21):149-55.

16. Christopher AE, Casimir N, Richard O. Microbiology of lower respiratory tract infections in Benin City, Nigeria. Malays J Med Sci 2011;18(2):27-31.

17. Kombade SP, Agrawal GN. Microbiological study of lower respiratory tract infections in ICU patients. Int J Curr Microbiol App Sci 2014;3(8):749-54.

18. Trupti B, Shrivastava G, Bhatambare GS, et al. Microbiological profile of lower respiratory tract infections in neurological intensive care unit of a tertiary care centre from central India. Journal of Basic and Clinical Pharmacology 2013;4(3):51-5.

19. Laifangbam S, Preeti G, Khongbantabam V. Trend of hepatitis $B$ and hepatitis $C$ infection in a tertiary care medical institute in eastern India. J Evolution Med Dent Sci 2016;5(35):2061-4.

20. Mahapatra A, Samal B, Pattnaik D, et al. Antimicrobial susceptibility pattern of clinical isolates of nonfermentative bacteria. Indian $\mathrm{J}$ pathol Microbiol 2003;46(3):526-7. 